CUM LAUDE

Revista del Doctorado en Derecho

Facultad de Derecho y Ciencias Sociales y Políticas UNNE

$\mathrm{N}^{\circ} 1$ - Diciembre 2014

Corrientes - Argentina

ISSN 2422-6408 (formato digital)

info@revistacumlaude.com

FECHA DE RECEPCIÓN: 17/03/2014

FECHA DE ACEPTACIÓN: 08/05/2014

\title{
EMBARGO DE FONDOS DEL ESTADO PROVINCIAL
}

\author{
MAURICIO GOLDFARB
}

UNIVERSIDAD NACIONAL DEL NORDESTE

\section{RESUMEN}

El Estado provincial puede ser objeto de ejecución y sus bienes pueden ser embargados en el caso de sentencias condenatorias firmes. Las normas que confieren el privilegio de inembargabilidad de los fondos solo resultan oponibles cuando no impliquen degradar y desconocer la sentencia firme. Tal degradación ocurre ante la falta de entrega de bonos -en los casos de deudas consolidadas- , la inexistencia de imputación presupuestaria y pago en un plazo razonable -para el caso de deudas no consolidadas-, y en cualquier otro supuesto donde exista una urgencia debidamente acreditada, por la naturaleza del crédito o por encontrarse el acreedor en situaciones especiales de desamparo o vulnerabilidad. 


\title{
Palabras Clave
}

Ejecución de sentencias - Inembargabilidad - Vulnerabilidad

\begin{abstract}
The provincial state may be subject to enforcement and assets seized in the case of firm convictions. The rules that confer the privilege of immunity from garnishment of the funds are only enforceable when not involve degrading and ignoring the judgment. Such degradation happens the lack of delivery of bonds, in the case of consolidated -or when the budget item and payment is not made in a reasonable term -the case of consolidated uncontested debts-and where there is otherwise duly qualified emergency situations or special vulnerability of the creditor.
\end{abstract}

\section{KEYWORDS}

Forced execution of judgments -Immunity of garnishment - Vulnerability

\section{INTRODUCCIÓN}

El objeto de este trabajo de investigación es analizar críticamente uno de los aspectos de la ejecución de las sentencias contra el Estado Provincial que se resuelven en el pago de sumas de dinero: la cuestión de la embargabilidad de los fondos. Si bien el estudio se centra en la 
normativa aplicable al caso particular de la Provincia de Corrientes, muchas de las apreciaciones resultan aplicables a los otros regímenes provinciales ${ }^{1}$.

La importancia del tema ya fue destacada por la doctrina nacional y provincial ${ }^{2}$, y se vincula en forma directa e inmediata con las garantías constitucionales del debido proceso, la tutela judicial efectiva y del derecho de propiedad, todas ellas de raigambre constitucional y supranacional.

Pocas cosas son más tristes para los titulares de los derechos lesionados -y para sus abogados- que obtener una sentencia favorable y, sin embargo, no verla realizada en tiempo y forma. Y ello resulta especialmente irritante, cuando se ha recorrido todo el largo y engorroso procedimiento administrativo y, agotado este, la vía judicial, peregrinar que en la mayoría de los casos lleva varios años ${ }^{3}$.

La idea central es brindar una descripción crítica del complejo procedimiento de cobro de acreencias al Estado Provincial y los supuestos en que el embargo de fondos resulta procedente. Pondremos especial énfasis en los aspectos prácticos de la cuestión, con referencia a los criterios jurisprudenciales vigentes en los órganos judiciales de máxima jerarquía.

\footnotetext{
${ }^{1}$ Por la similitud de las normas constitucionales y legales y por el ámbito de aplicación de la ley 25.793, como más abajo se verá.

${ }^{2}$ Véase el muy interesante trabajo incluido por Gustavo A. Revidatti como anexo de "Lo Contencioso Administrativo", titulado "Ejecución de la Sentencia dictada en el Proceso Administrativo o Contencioso Administrativo", Cicero Ediciones, 1986.

${ }^{3}$ En el caso particular de la provincia de Corrientes, hasta la sanción de la nueva Constitución de 2007, los asuntos contencioso administrativos tramitaban en instancia originaria y única ante el Superior Tribunal de Justicia de Corrientes. A partir de la reforma y la sanción de la ley 5846 de creación del Fuero Contencioso Administrativo en la Provincia de Corrientes se estableció un sistema de Juzgados con competencia en lo Contencioso de primera instancia en toda la provincia, una Cámara de Apelaciones en lo Contencioso y Electoral, y el eventual recurso extraordinario ante el Superior Tribunal, lo que sin lugar a dudas prolongará la duración de los procesos contencioso administrativos, sin perjuicio de los beneficios de contar con un fuero especializado.
} 


\section{Ejecución de Sentencias. El Sistema de pago de las deudas del estado}

\section{PROVINCIAL}

Antes de tratar el tema del embargo de los fondos en sí, es necesario ubicarlo dentro del marco del proceso de ejecución de sentencias. Empezaremos entonces por formular un esquema del sistema de pago de las acreencias del Estado cuando las mismas resultan de condenas judiciales firmes. Este régimen corresponde a las deudas no alcanzadas por algunas de las leyes de Consolidación de Deudas, porque en tales casos, el pago y cancelación se rige por las leyes 4558/4726 y el Decreto Ley 106/00 .

De acuerdo al sistema previsto en el orden nacional por la ya citada ley 24.624 , y reproducido por la ley 5689 en el orden provincial, el procedimiento a seguir en caso de una sentencia que ordena el pago de una suma de dinero por parte del Estado provincial es el siguiente:

a) Una vez que la sentencia queda firme ${ }^{5}$, el particular debe solicitar el pago de su acreencia por ante la propia Administración ${ }^{6}$.

b) Con dicha presentación, se forma un expediente administrativo, y luego del procedimiento correspondiente y la intervención de los organismos pertinentes, se dispone el pago de la deuda, siguiendo un estricto orden de antigüedad conforme la fecha de notificación judicial, y siempre y cuando exista crédito presupuestario.

c) Para el caso de no existir tal crédito, deberán efectuarse las previsiones necesarias a fin de su inclusión en el ejercicio siguiente, comunicando a la Dirección de Presupuesto del

\footnotetext{
${ }^{4}$ Reglamentado por Decreto 792/01.

${ }^{5}$ El particular puede optar por la liquidación judicial o administrativa de su acreencia. En el caso de que opte por la judicial, sin perjuicio de su mayor validez, deberá consumir el tiempo procesal correspondiente.

${ }^{6}$ A tal fin se ha aprobado un formulario de requerimiento que puede descargarse de la página de la Fiscalía de Estado de Corrientes (www.fiscalia.gov.ar)
} 
Ministerio de Hacienda y Finanzas de la Provincia el monto que corresponde abonar antes del día 31 de agosto, a fin de su inclusión en el proyecto de presupuesto del año siguiente. Aprobado el mismo, con el inicio del año fiscal deberá procederse al pago, siguiendo nuevamente el orden de prelación, de los más antiguos a los más nuevos.

\section{REFLEXIONES CRÍTICAS RESPECTO DEL SISTEMA DE PAGO}

Es evidente que el sistema antes descripto tiene claras reminiscencias kafkianas. Luego de un largo y lento procedimiento administrativo que le es desfavorable ${ }^{7}$, el particular recurre a la Justicia buscando respuesta a su reclamo. Sorteados con éxito los múltiples obstáculos del proceso judicial -su trámite ordinario, la vía recursiva ordinaria y la extraordinaria- el particular -junto a su letrado- levanta ahora triunfante la copia certificada de su sentencia favorable y firme, solo para iniciar un nuevo procedimiento administrativo que le permita el cobro de su acreencia ${ }^{8}$.

Se trata de una de las típicas prerrogativas públicas de las que goza el Estado para el cumplimiento de sus fines (Cassagne, 1998, p. 1), un ejemplo más de la tensión entre poder y los derechos de los particulares, que el Derecho en general y el Derecho Administrativo en especial están llamados a equilibrar (Balbín, 2013, p. 278).

La idea que anima este privilegio en particular es permitir al Estado tomar las previsiones presupuestarias correspondientes, para evitar ser "sorprendido" por el requerimiento de pago. Entonces, ante el crédito firme y líquido debe verificar si cuenta con las partidas presupuestarias suficientes, y en caso negativo, preverlas para el ejercicio siguiente.

\footnotetext{
${ }^{7}$ Exceptuando los pocos casos en que el reclamo previo no es obligatorio.

${ }^{8}$ Con gran sentido literario, Gordillo $(2009$, p. 641) reflexiona: "Ganarle un juicio al Estado parece Crimen y Castigo. Al crimen de iniciar un juicio porque se quiere la reparación del perjuicio ocasionado por el Estado, el condigno castigo de ganarlo y tener que empezar entonces todo de vuelta, a peregrinar y mendigar por cuanta oficina pública, judicial y administrativa fuera menester (y con honestidad y suerte, ninguna privada), además de a veces legislativa para que aprueben el crédito.
} 
Como señaló la Corte Suprema de Justicia, el propósito del legislador fue el de evitar que la administración pueda verse situada por imperio de un mandato judicial perentorio en el trance de no poder satisfacer el requerimiento por no tener los fondos previstos en el presupuesto para tal fin (Balbín, 2013, p. 278) ${ }^{11}$.

Sin embargo, el fundamento expuesto para justificar tales recaudos resulta sólido solo en apariencia. De acuerdo a la normativa vigente, al iniciar una demanda, y antes de correr traslado de la misma, debe acreditarse la notificación a la Fiscalía de Estado de la provincia la existencia de la demanda, el tribunal de radicación y el monto reclamado ${ }^{12}$. En este momento ya podría realizarse -al menos- una previsión de pago de la acreencia reclamada. Esta previsión debería ser considerada, como un pasivo eventual, que permita luego cancelarlo en el caso de existir una sentencia desfavorable a los intereses estatales. Además, el control que realizan los letrados de la Fiscalía de Estado durante todo el desarrollo del proceso, les permite informar la mayor probabilidad de condena firme, tanto con la sentencia de primera instancia, como la de Cámara o la que en su caso dicten el Superior Tribunal de Justicia de Corrientes o la Corte Suprema de Justicia de la Nación.

A lo largo de todo este devenir, que normalmente insume largos años y que puede constituir una afectación del derecho a la tutela judicial efectiva ${ }^{13}$ es evidente que resoluciones judiciales que confirmen la procedencia del reclamo hacen aún más probable un reclamo de

\footnotetext{
${ }^{11}$ Fallos: 322:2132.

${ }^{12}$ Artículo 42 de la Ley 5853 de Fiscalía de Estado, que sustituyó a la notificación similar ya vigente por Decreto 106/00 y su modificatorio 113/01. El formulario de "Alta en el Registro de Juicios" también puede descargarse en la página www.fiscalia.gov.ar

${ }^{13}$ Implícita en los artículos 18 y 33 de nuestra Constitución Nacional y expresamente reconocida en los artículos 8.1 y 25 del Pacto de San José de Costa Rica, 8 y 10 de la Declaración Universal de los Derechos del Hombre y el artículo 14 del Pacto Internacional de Derechos Civiles y Políticos, todos instrumentos con jerarquía constitucional de acuerdo al artículo 75 inc. 22 de la Constitución Nacional. Se trata de una garantía fundamental porque es instrumental, necesario e imprescindible para para el ejercicio de los otros derechos fundamentales. Ver en Balbín, (2013, p. 167).

Recomendamos la lectura del contundente fallo de la Corte Interamericana de Derechos Humanos en el Caso "Furlán y familiares vs. Argentina" Sentencia del 31 de agosto de 2012. En el mismo se condenó al Estado argentino por violación de los artículos 5.1, 8.1, 21, 25.1 y 25.2.c del Pacto de San José de Costa Rica. La sentencia puede consultarse en www.corteidh.or.cr/docs/casos/articulos/seriec_246_esp.pdf
} 
pago de dicho crédito. Por ello el Estado puede y debe prever como hacer frente a dicho reclamo. Quedaría excluido de este supuesto el caso de que todas las instancias fueran adversas al actor y que recién se acogiera su demanda en la última instancia, supuesto posible, pero poco probable, conforme lo demuestra la experiencia.

Por otra parte, la ley 5689 no prevé plazo para el cumplimiento del pago, contado desde el inicio del expediente de requerimiento de pago. Para el caso de las causas de naturaleza contencioso-administrativas, al no haber sido derogado, resulta de aplicación el plazo de 6 meses fijado por el artículo 107 de la ley $4106^{14}$. No existe una solución legal prevista para el caso de que el crédito pueda cancelarse solo parcialmente ${ }^{15}$. Tampoco se ha previsto el plazo de cumplimiento cuando no existe partida presupuestaria suficiente. Por elementales razones lógicas, el pago debería producirse a partir de la aprobación del nuevo presupuesto, dentro de un plazo razonable.

Otro supuesto que no se halla previsto en el régimen antes descripto, es que ocurre cuando en el presupuesto del año siguiente tampoco se prevé el crédito suficiente, o el mismo agota sus partidas antes del pago de la obligación en particular.

Ante estas u otras dificultades que se presenten para hacer efectivo el crédito, por elementales razones de economía procesal y respeto a la cosa juzgada, se debe realizar el planteo directamente en sede judicial ante el tribunal interviniente, y como parte de la ejecución de la sentencia.

\footnotetext{
${ }^{14}$ Ley 4106, Artículo 107: Plazo de ejecución. La autoridad administrativa vencida en juicio, gozará de sesenta (60) días, contados desde la notificación de la sentencia condenatoria, para dar cumplimiento a las obligaciones impuestas salvo que se tratare de pagar una deuda en cuyo caso no podrá ser ejecutada, ni embargado sus bienes, debiendo la Legislatura arbitrar el modo y forma de verificar dicho pago. La ley se dictará dentro de los seis (6) meses de consentida o ejecutoriada la sentencia, bajo pena de quedar sin efecto este privilegio. Ver Rubín (2008). En el caso de las sentencias civiles, el juez deberá fijar el plazo razonable, o aplicar por analogía el mismo plazo.

${ }^{15}$ Lo que necesariamente requerirá la aceptación del acreedor (arg. 505 C. Civil).
} 
Formulados estos reparos, a continuación analizaremos la cuestión del embargo en el proceso de ejecución de sentencias contra el Estado.

\section{EL PRINCIPIO GENERAL: LA REgUlaCión CIVIL DE LAS RELACIONES DEUdOR -}

\section{ACREEDOR}

Para considerar en particular la cuestión del embargo de los fondos, resulta necesario recordar que la regulación de las relaciones entre deudores y acreedores es materia de la legislación de fondo civil y esta materia ha sido expresamente delegada al gobierno federal por las provincias ${ }^{16}$.

Al ser las provincias personas jurídicas, la regla es que pueden ser demandadas y como consecuencia del cumplimiento de las sentencias dictadas en sede judicial, que puede "hacerse ejecución en sus bienes"17. Dicha "ejecución" presupone, a su vez, y como antecedente necesario ${ }^{18}$ el "embargo" de los bienes que han de ser ejecutados.

16 Constitución Nacional, Artículo 75.- Corresponde al Congreso:...12. Dictar los Códigos Civil, Comercial, Penal, de Minería, y del Trabajo y Seguridad Social, en cuerpos unificados o separados, sin que tales códigos alteren las jurisdicciones locales, correspondiendo su aplicación a los tribunales federales o provinciales, según que las cosas o las personas cayeren bajo sus respectivas jurisdicciones; y especialmente leyes generales para toda la Nación sobre naturalización y nacionalidad, con sujeción al principio de nacionalidad natural y por opción en beneficio de la argentina: así como sobre bancarrotas, sobre falsificación de la moneda corriente y documentos públicos del Estado, y las que requiera el establecimiento del juicio por jurados.

${ }_{17}$ Argumento a tenor del artículo 42 del Código Civil.

${ }^{18}$ Así lo dispone el artículo 561 del Código Procesal Civil y Comercial de Corrientes: "Es requisito del trámite de cumplimiento de la sentencia de remate, la traba de embargo". 
Por ello, los bienes del Estado provincial pueden ser embargados y ejecutados en el cumplimiento de las sentencias dictadas por los tribunales. Esta conclusión resulta de la interpretación armónica de los artículos 42 y 33 del Código Civil ${ }^{19}$.

El principio es, entonces, el de la embargabilidad de los bienes públicos dentro del proceso judicial, regla que no es sino una derivación lógica del sometimiento del Estado al orden jurídico. Este acatamiento del Estado a las decisiones judiciales ha sido expresamente reconocido en el ámbito de nuestra provincia por la Constitución de Corrientes, que en su artículo 20 reza: "El Estado, como persona civil, puede ser demandado ante los Tribunales ordinarios, sin necesidad de autorización previa del Poder Legislativo."

\section{LAS NORMAS QUE DISPONEN LA INEMBARGABILIDAD DE LOS FONDOS PROVINCIALES}

\subsection{El artículo 20 de la Constitución de la Provincia de Corrientes}

Establecido que el principio general es la posibilidad de embargo sobre los bienes de los estados provinciales, pasamos ahora a la cuestión específica del embargo de fondos en el procedimiento de ejecución de sentencia. Ya hicimos referencia la primera parte del artículo 20 de la Constitución de Corrientes, que reafirma el principio de demanda, sin autorización previa $^{20}$. Pero el texto constitucional correntino, que no obstante la reforma de 2007 mantiene el texto original de $1960^{21}$ agrega a renglón seguido que:

${ }^{19}$ Artículo 42 del Código Civil: "Las personas jurídicas pueden ser demandadas por acciones civiles, y puede hacerse ejecución en sus bienes". Artículo 33: “Las Personas jurídicas pueden ser de carácter público o privado. Tienen carácter público: $1^{\circ}$. El Estado Nacional, las Provincias y los Municipios”.

${ }^{20}$ Normas similares aparecen en las constituciones de las provincias del Chaco (artículo 96), Formosa (artículo 34) y Misiones (artículo 81).

${ }^{21}$ La Constitución reformada no solo mantuvo la redacción de 1960, sino que además amplió este privilegio a las Municipalidades. "Artículo 230: Si una Municipalidad es condenada al pago de una deuda, sus rentas o bienes sólo pueden ser embargados cuando el órgano municipal competente no 
Sin embargo, si fuere condenado al pago de una deuda, no podrá ser ejecutado en la forma ordinaria ni embargados sus bienes, debiendo la Legislatura arbitrar el modo y forma de verificar dicho pago. La ley se dictará dentro de los seis meses de consentida la sentencia, bajo pena de quedar sin efecto este privilegio $^{22}$.

A diferencia de lo que más adelante veremos como objeto principal de análisis, la prohibición de embargo constitucional no comprende solo a los fondos, sino que abarca a todos los bienes de propiedad provincial.

\subsubsection{InConstitucionalidad del ARTículo 20 de la Constitución de la Provincia DE CORRIENTES}

Este segundo párrafo del artículo 20 de la Constitución de la Provincia de Corrientes ha sido declarado inconstitucional por la Corte Suprema de Justicia de la Nación, a partir del caso "Guglioni de Leiva"23. En dicho leading case la Corte Suprema sostuvo que:

El art. 20 de la Constitución de la Provincia de Corrientes en cuanto dispone la exención de ejecución y embargo a favor del Estado provincial durante el plazo de seis meses es inconstitucional, en tanto concede privilegios en pugna con la legislación de fondo dictada por el Congreso...

arbitre el modo y forma de verificar el pago dentro de los seis (6) meses de la fecha en que quede firme la sentencia. En ningún caso deben ser embargados los bienes afectados a la prestación de servicios públicos.” En la redacción anterior, el artículo correspondía al número 166. Ver Midón (2008).

${ }^{22}$ En el mismo sentido el Código de Procedimientos Contencioso Administrativo de Corrientes (Ley 4106): Ejecución de la sentencia. Artículo 107.- Plazo de ejecución. La autoridad administrativa vencida en juicio, gozará de sesenta (60) días, contados desde la notificación de la sentencia condenatoria, para dar cumplimiento a las obligaciones impuestas salvo que se tratare de pagar una deuda en cuyo caso no podrá ser ejecutada, ni embargado sus bienes, debiendo la Legislatura arbitrar el modo y forma de verificar dicho pago. La ley se dictará dentro de los seis (6) meses de consentida o ejecutoriada la sentencia, bajo pena de quedar sin efecto este privilegio.

${ }^{23}$ Fallos 303:1801. 
Las provincias son por el Código Civil, arts. 33 y 42, personas jurídicas de existencia necesaria, demandables y susceptibles de ser ejecutadas; consagrada la unidad de la legislación civil como consecuencia de la unidad política de la República, no cabe admitir que los estados autónomos puedan destruir aquélla, al dictar sus constituciones, concediéndose ellos mismos privilegios o exenciones al margen de la legislación general.

El argumento central que utiliza la Corte Suprema para tal declaración de inconstitucionalidad se refiere a la competencia de las provincias para regular el régimen de bienes, competencia que corresponde al Congreso de la Nación (artículo 75 inc. 12) ${ }^{24}$, en virtud de la expresa delegación provincial. Sin embargo, el criterio que la misma Corte Suprema sostiene es distinto en relación a los privilegios decretados por leyes del Congreso de la Nación, y en resguardo de los intereses del Estado Nacional ${ }^{25}$.

A pesar del fallo del máximo tribunal de la Nación, en la Provincia de Corrientes siguieron dictándose leyes que prohibían el embargo de bienes del Estado provincial ${ }^{26}$. La misma restricción de embargo fue incluida en las distintas leyes de consolidación de deudas dictadas en la Provincia de Corrientes. Desde 1991 a 2000 se han sancionado tres leyes de Consolidación de Deudas: La ley 4558, que consolida las deudas cuya

\footnotetext{
${ }^{24} \mathrm{Al}$ momento del dictado del fallo en la causa "Guglioni de Leiva" (1981), el art. era el 67 inc. 11.

25 Esta diferencia en la tutela a los bienes del Estado Nacional por encima de los de los Estados Provinciales ya fue resaltada por Revidatti en el trabajo antes citado, ver ob. cit. p. 176.

${ }^{26}$ El texto se repite casi sin variaciones en todas las normas. A título de ejemplo, se transcribe el de la ley 5415: Artículo $1^{\circ}$.- DECLARÁSE inembargable en cualquier tipo de causa, incluidas las acciones de amparo, por seis (6) meses, renovables por igual término por Decreto del Poder Ejecutivo, los fondos que pertenezcan al Estado Provincial (Administración Central, Entes Autárquicos y Descentralizados) y a las Municipalidades de Primera, Segunda y Tercera Categorías, ya sea que los mismos provengan de coparticipación en los Impuestos Nacionales o Provinciales, Tasas, Contribuciones por Mejoras, Aportes del Tesoro Nacional, Transferencias de Fondos de origen nacional con afectaciones específicas, Regalías o provenientes por cualquier otro concepto. En caso de hacerse efectiva la prórroga autorizada, la misma deberá comprender a las Municipalidades antes citadas.
} 
causa sea anterior al 01/04/91, la ley 4726 que prorroga la fecha de corte de la ley anterior hasta el 03/02/92 $2^{27}$ y por último el Decreto Ley 106/00 que consolidó todas las deudas de causa anterior al 01/01/00.

La Corte Suprema de Justicia de la Nación ha declarado la validez de los regímenes que suspenden la ejecutoriedad de las sentencias, difieren las obligaciones estatales y establecen pagos en bonos a partir de los casos "Peralta",28 en el orden nacional y "Videla Cuello"29 en relación a las provincias. La compatibilidad de estos regímenes de excepción con la Constitución fue ratificada por la Corte Federal, con algunas excepciones que veremos más adelante. En 2004 al resolver la constitucionalidad de la pesificación de los depósitos en "Bustos" 30 , la Corte volvió a ratificar su doctrina, luego de haberla puesto en crisis con los fallos "Smith" y "Provincia de San Luis",

\subsection{LA LEY 25.793}

${ }^{27}$ Declarada inconstitucional por la Corte Suprema de Justicia de la Nación por exceder la fecha fijada por la ley nacional 23.982, introduciendo alteraciones que significan condiciones más gravosas para los acreedores, en los autos "Agüero, Luis y otra c. Estado de la Provincia de Corrientesy otros s/Ordinario" sentencia del 12/08/03, con expresa remisión a la doctrina de Fallos 324:363.

28 "Peralta, Luis A. y otro c. Estado Nacional, Ministerio de Economía, Banco Central s/Amparo" sentencia del 27/12/90 (Fallos 313:1513).

29 "Videla Cuello, Marcelo c. Provincia de la Rioja” sentencia del 27/12/90 (Fallos 313:1638).

30 "Bustos, Alberto Roque y otros c. Estado Nacional y otros s/Amparo", sentencia del 26/10/04 (Fallos 327:4495).

31 "Banco de Galicia y Buenos Aires s/ Solicita intervención urgente en autos: "Smith, Carlos A. c/Poder Ejecutivo Nacional o Estado Nacional s/Sumarísimo" resuelto el 01/02/2002 (Fallos: 325:28) y "Provincia de San Luis c. Estado Nacional s/Amparo" sentencia del 5/03/03 (Fallos 326:417) La evolución de la jurisprudencia de la Corte Suprema y las críticas a estas fluctuaciones pueden revisarse en Gelli (2008, t. II, p. 272 y ss.) 
El respaldo normativo de la inembargabilidad se modificó radicalmente, cuando el Congreso de la Nación sancionó la ley $25.793^{32}$, a la que la provincia de Corrientes adhirió por ley provincial $5689^{33}$.

La ley 25.793 estableció en su artículo 1: "Declárase aplicable en beneficio de las provincias, los municipios y de la Ciudad Autónoma de Buenos Aires, en relación a los fondos públicos que le pertenecen, el régimen de inembargabilidad establecido por los artículos 19 y 20 de la Ley $24.624^{34}$ y sus normas complementarias, o las que en el futuro las sustituyan.

La ya mencionada ley provincial 5689 en su art. 1 adhiere a la ley nacional 25.793 , y luego reproduce -con leves modificaciones- los arts. 19 y 20 de la ley $24.264^{35}$.

\footnotetext{
${ }^{32}$ Publicada en el Boletín Oficial de la Nación el 31/12/2004.

${ }^{33}$ Publicada en el Boletín Oficial de la Provincia el 30/11/2005.

${ }^{34}$ Que a su vez, dichos artículos 19 y 20 de la ley 24.624 establecen que: "Art. 19 - Los fondos, valores y demás medios de financiamiento afectados a la ejecución presupuestaria del Sector Publico, ya sea que se trate de dinero en efectivo, depósitos en cuentas bancarias, títulos, valores emitidos, obligaciones de terceros en cartera y en general cualquier otro medio de pago que sea utilizado para atender las erogaciones previstas en el Presupuesto General de la Nación, son inembargables y no se admitirá toma de razón alguna que afecte en cualquier sentido su libre disponibilidad por parte del o de los titulares de los fondos y valores respectivos. Lo dispuesto en este articulo es de aplicación para cualquier clase de cuenta o registro a nombre del Estado Nacional o de cualquiera de sus organismos o dependencias del PODER LEGISLATIVO, PODER JUDICIAL, PODER EJECUTIVO, Ia AUDITORIA GENERAL DE LA NACION, la DEFENSORIA DEL PUEBLO y el MINISTERIO PUBLICO y la ADMINISTRACION PUBLICA NACIONAL centralizada y descentralizada, entidades autárquicas y MUNICIPALIDAD DE LA CIUDAD DE BUENOS AIRES. Quienes en virtud de su cargo hubieren tomado razón de alguna medida judicial comprendida en lo que se dispone en el presente, comunicaran al tribunal la imposibilidad de mantener vigente la medida en virtud de lo que se dispone en esta ley. En aquellas causas judiciales donde el Tribunal, al momento de la entrada en vigencia del presente, hubiere ordenado la traba de medidas comprendidas en las disposiciones precedentes, y los recursos afectados hubiesen sido transferidos a cuentas judiciales, los representantes del Estado Nacional que actúen en la causa respectiva, solicitarán la restitución de dichas transferencias a las cuentas y registros de origen, salvo que se trate de ejecuciones validas firmes y consentidas con anterioridad a la fecha de entrada en vigencia de la presente ley.
}

${ }^{35}$ Ley 5689, "Artículo $2^{\circ}$.- Los fondos, valores y demás medios de financiamiento afectados a la ejecución presupuestaria del sector público provincial, ya sea que se trate de dinero en efectivo, depósitos en cuentas bancarias, títulos, valores emitidos, obligaciones de terceros en cartera y en general cualquier otro medio de pago que sea utilizado para atender las erogaciones previstas en el Presupuesto General de la Provincia, son inembargables y no se admitirá toma de razón alguna que afecte en cualquier sentido su libre disponibilidad por parte del o de los titulares de los fondos y valores respectivos. 
A partir de la ley 25.793, es una norma legal de orden federal la que dispone la inembargabilidad, por lo que el fundamento de la inconstitucionalidad en razón del exceso de competencia por parte de la provincia queda desechado ${ }^{36}$.

Una cuestión interesante para el debate es verificar si ha existido un exceso de parte de la provincia al extender la inembargabilidad a los "entes y organismos centralizados y descentralizados, a los entes autárquicos del Estado Provincial, a las sociedades con participación estatal mayoritaria, a los entes u organizaciones empresarias o societarias donde el Estado Provincial o sus entes de cualquier naturaleza tengan participación total o parcial" porque la ley 25.793 solo declaraba aplicable la restricción "en beneficio de las provincias, los municipios y la Ciudad Autónoma de Buenos Aires...”. Sin perjuicio de que, como ya vimos, las provincias no pueden regular la materia, creemos que la autorización solo alcanza a los Estados provinciales y municipales ${ }^{37}$, y que extender el privilegio inclusive a "entes $u$ organizaciones empresarias o societarias donde el Estado Provincial o sus entes de cualquier naturaleza tengan participación total o parcial", resulta excesivo y sin fundamento constitucional ${ }^{38}$. A nuestro juicio, este exceso determina su invalidez, por los mismos argumentos de las normas de inembargabilidad anteriores, esto es, la imposibilidad de los estados provinciales de regular las

Quienes, en virtud de su cargo, hubieren tomado razón de alguna medida judicial comprendida en lo que se dispone en el presente, comunicarán al tribunal la imposibilidad de mantener vigente la medida en virtud de lo que se dispone en esta Ley.

En aquellas causas judiciales donde el Tribunal, al momento de la entrada en vigencia del presente, hubiere ordenado la traba de medidas comprendidas en las disposiciones precedentes, y los recursos afectados hubiesen sido transferidos a cuentas judiciales, los representantes del Estado Provincial que actúen en la causa respectiva, solicitarán la restitución de dichas transferencias a las cuentas y registros de origen, salvo que se trate de ejecuciones válidas firmes y consentidas con anterioridad a la fecha de entrada en vigencia de la presente Ley".

${ }^{36}$ Argumento central de la Corte Suprema de Justicia de la Nación en el ya referido caso "Guglioni de Leiva".

${ }^{37}$ Esta es la posición de Dromi (2009, pp. 1299-1300)

${ }^{38}$ Pero en tal caso, el planteo del embargo deberá contener además el de la inconstitucionalidad de tal extensión, con los fundamentos ya vistos respecto de las ausencias de facultades provinciales para regular la materia. 
normas que rigen la relación deudor - acreedor, materia eminentemente civil, y como tal delegada al Estado Federal (artículo 75 inc. 12 de la Constitución Nacional).

\section{EXCEPCIONES A LA INEMBARGABILIDAD DE LOS FONDOS}

Ya hemos visto que las provincias son demandables, y sus bienes pueden ser objeto de ejecución y embargo. También hemos pasado revista a las normas federales y locales que excluyen a los fondos estatales de la posibilidad de embargo.

Ahora consideraremos el caso en el cual el Estado no cumple con el pago del monto de condena fijado judicialmente. Nos situamos entonces en el supuesto de que la Sentencia se halla firme y no cumplida efectivamente, ni siquiera a través de los procedimientos privilegiados a favor del Estado.

Esta situación constituye una afectación del derecho a la tutela judicial efectiva que presupone el efectivo cumplimiento de las sentencias ${ }^{39}$. La falta de cumplimiento de las sentencias constituye una nueva violación de los derechos de los particulares, que se suma a la que diera lugar a la promoción de la acción.

En esta hipótesis, no cabe otra vía que la ejecución de la sentencia, por el trámite previsto en los códigos de procedimientos respectivos, aplicables según el fuero en el que tramite el proceso $^{40}$. Y como trámite necesario para la ejecución, corresponde el embargo de los bienes del ejecutado. Cabría la posibilidad, al menos en el plano teórico de que el ejecutante embargara un bien distinto de dinero en efectivo o títulos (p.e. un inmueble del dominio privado del Estado). En tal caso, no existe norma ni constitucional ni legal que impida el embargo. Si bien lo más común es que se embargue dinero, por la facilidad del cobro posterior, no puede

\footnotetext{
${ }^{39}$ Recomendamos la lectura del contundente fallo de la Corte Interamericana de Derechos Humanos en el Caso "Furlán y familiares vs. Argentina" Sentencia del 31 de agosto de 2012. En el mismo se condenó al Estado argentino por violación de los artículos 5.1, 8.1, 21, 25.1 y 25.2.c del Pacto de San José de Costa Rica. La sentencia puede consultarse en www.corteidh.or.cr/docs/casos/articulos/seriec_246_esp.pdf ${ }^{40}$ Gallegos Fedriani, (2007).
} 
soslayarse la posibilidad del embargo sobre un bien respecto del cual no existe prohibición legal de embargo

Pero en el caso más común de que se embarguen fondos estatales ¿Cuáles serían los supuestos en que podrían los jueces declarar la inaplicabilidad de las leyes 25.793 y 5.689 y por consiguiente disponer el embargo de fondos provinciales?

La Corte Suprema de Justicia de la Nación y el Superior Tribunal de Justicia de Corrientes se han expedido respecto de los casos en los que procede el embargo sobre fondos de propiedad estatal, no obstante la vigencia de la normativa de inembargabilidad. Todos los casos tienen en común una afectación al derecho a la tutela judicial efectiva, por la desnaturalización de la sentencia, y una violación al derecho de propiedad ${ }^{41}$, por el empobrecimiento del acreedor y el enriquecimiento correlativo y sin causa del Estado ${ }^{42}$.

La Corte Federal, haciendo suyo el dictamen de la Procuradora ha sostenido como regla general que la compatibilidad constitucional de los sistemas de moratorias estatales -como los que establecen las leyes de consolidación- debe valorarse en el caso concreto, y dependerá de que no signifique una degradación tal que destruya la sustancia del derecho reconocido en la sentencia judicial ${ }^{43}$.

Como ya hemos dicho, la cuestión de si deben inaplicarse las normas que protegen del embargo a los fondos estatales es una cuestión que debe examinarse en cada caso concreto. No

\footnotetext{
${ }^{41}$ Reconocido en el artículo 17 de la Constitución Nacional y en los tratados de derechos humanos, v. gr. el artículo 21 de la Convención Americana de Derechos Humanos: "Artículo 21. Derecho a la Propiedad Privada 1. Toda persona tiene derecho al uso y goce de sus bienes. La ley puede subordinar tal uso y goce al interés social. 2. Ninguna persona puede ser privada de sus bienes, excepto mediante el pago de indemnización justa, por razones de utilidad pública o de interés social y en los casos y según las formas establecidas por la ley."

${ }^{42}$ Con su habitual agudeza, Gordillo (2009, p. 635) señala que: "Los daños se siguen cometiendo y las indemnizaciones llegan cada vez menos y más menguadas a los perjudicados. Casi nadie ve enteramente reparado de su daño, mucho menos en un tiempo razonable. Todos los tiempos son irrazonables y, como se verá, las sumas también."

43 "Aliprandi, Luisa cl PAMI s/sumario", fallada el 23 de febrero de 2010. Dictamen de la Procuradora Dra. Laura Monti del 27 de octubre de 2008.
} 
obstante, creemos que pueden agruparse los supuestos principales en que el embargo procede, y como han sido admitidos en la jurisprudencia, como detallaremos a continuación.

\subsection{FALTA DE ENTREGA DE LOS BONOS DE CONSOLIDACIÓN}

El embargo será procedente cuando la deuda, no obstante estar comprendida en el régimen de consolidación no es satisfecha con la entrega de los bonos correspondientes, y tampoco se cumple con el pago en efectivo.

Este supuesto ha sido contemplado expresamente por la Corte Suprema de Justicia de la Nación, en autos "Dimensión Integral de Radiodifusión SRL c/Provincia de San Luis" fallada el 13/03/07. Allí, el máximo tribunal de la Nación resolvió: "Que no empece a lo expuesto la previsión contenida en el artículo $1^{\circ}$ de la ley 25.793, toda vez que esa disposición legal no trae aparejada una suerte de autorización al Estado Provincial para no cumplir las sentencias judiciales, pues ello importaría tanto como colocarlo fuera del orden jurídico ${ }^{, 44}$.

El sistema de consolidación de deudas constituye un claro privilegio a favor del Estado, y la falta de cumplimiento por parte del mismo Estado, no puede sino dejar expedita la vía de ejecución ordinaria de la sentencia condenatoria, que como vimos presupone el embargo de bienes del deudor. Por último, creemos importante destacar que a fin de evitar perjuicios innecesarios, los fondos sobre los que se puede trabar embargo son aquellos que no tienen asignación específica (p.e. rentas generales) ${ }^{45}$.

\footnotetext{
44 "En ese sentido se ha pronunciado este Tribunal en reiteradas oportunidades, y a los fundamentos y conclusiones expuestos en esas ocasiones cabe remitirse en razón de brevedad (conf. Causas C.276 XXXIX "Caja Complementaria de Previsión Social para la Actividad Docente c/Jujuy, Provincia de s/ejecución fiscal", sentencia del 8 de noviembre de 2005; D.583 XXXVIII "Dresdner Forfaitierungs Aktieengesellschaft c/San Luis, Provincia de s/cobro de sumas de dinero" pronunciamiento del 11 de julio de 2006; S1119.XXXI "Santiago del Estero, Provincia de c/Gobierno Nacional s/Acción de Amparo - Incidente de ejecución de honorarios del doctor Raúl E. Mariscotti" sentencia del 21 de noviembre de 2006; entre otros. " Fallo citado, considerando 5.

${ }^{45} \mathrm{Si}$ bien de acuerdo al Presupuesto General de Gastos a cada gasto le corresponde un recurso, existen ciertos fondos que tienen asignación específica (p.e. transferencias nacionales para FONAVI).
} 


\subsection{FALTA DE IMPUTACIÓN PRESUPUESTARIA O DE PAGO EN TIEMPO RAZONABLE}

Otro supuesto de pérdida del privilegio de inembargabilidad tiene lugar en los casos de falta de imputación presupuestaria para el ejercicio siguiente o cuando de algún modo el pago no se realiza en un plazo razonable.

También en este caso el fundamento para no aplicar la normativa de excepción de embargo es similar: Cuando el propio Estado no cumple con los plazos privilegiados ${ }^{46}$ fijados para cancelar sus obligaciones, queda expedita la vía de ejecución ordinaria.

La Corte Suprema ha señalado que la dilación indefinida o por un tiempo irrazonable de la ejecución de sentencias contra el Estado deviene inconstitucional por afectación de principios constitucionales y supranacionales de igual jerarquía. El derecho a la tutela judicial efectiva incluye el derecho a ejecutar las sentencias contra el Estado.

El art. 19 de la ley 24.624 fue sancionado por el Congreso de la Nación para imponer pautas racionales en el cumplimiento de las obligaciones a cargo del Estado evitando el desvío de los recursos presupuestarios y los trastornos consiguientes que en la economía del sector público pueda producir tal desvío (confr. "La Austral" considerando 10 y su cita). Para expresarlo con las palabras empleadas por el Tribunal en el conocido precedente "Pietranera" (Fallos: 265:291) -cuya doctrina es plenamente compatible con el criterio adoptado in re: "La Austral" (ver considerando 10)- el propósito de la norma no es otro que el de evitar que la administración pueda verse situada por imperio de un mandato judicial perentorio en el trance de no poder satisfacer el requerimiento por no tener los fondos previstos en el presupuesto para tal fin o en la de perturbar la marcha normal de la administración. Sin embargo, de ello no se sigue que el Estado se encuentre fuera del orden jurídico que está obligado a tutelar

\footnotetext{
${ }^{46}$ La propia Constitución de la Provincia de Corrientes establece la condición bajo "bajo pena de quedar sin efecto este privilegio." El mismo apercibimiento está previsto en el ya citado artículo 107 de la ley 4106.
} 
ni que esté exento de acatar los fallos judiciales. Por lo pronto, el art. 19 de la ley 24.624 debe ser interpretado de modo tal que armonice con los principios y garantías consagrados por nuestra Ley Fundamental y con el resto del ordenamiento jurídico (Fallos: 296:22 y 302:1209, entre otros). ${ }^{47}$

En el Expediente 31855/2 caratulado: "Incidente de Medida Cautelar en autos Incidente de Ejecución de Honorarios en autos "Consiliaria Empresa Argentina de Consultas Sociedad Anónima y otro c/Municipalidad de la Ciudad de Corrientes s/Ordinario”, con fecha 02/12/08 el Superior Tribunal de Justicia de Corrientes dispuso el embargo de fondos de la Municipalidad, con fundamento en la falta de previsión de pago de la deuda. Allí se resolvió que: "No resulta en cambio que a pesar de ese extenso tiempo transcurrido desde la sentencia que condenó al pago de la obligación por honorarios que se ejecuta, la Municipalidad deudora hubiera efectuado la previsión presupuestaria pertinente" ${ }^{48}$

El Superior Tribunal de Justicia de Corrientes reproduce aquí el argumento vertido por la Corte Federal en el fallo "Dimensión Integral de Radiodifusión” -y los allí citados- de que "la previsión contenida en el art. $1^{\circ}$ de la ley 25973 no significa una suerte de autorización a

47 “Giovagnoli, César A. c. Caja Nacional de Ahorro y Seguro" sentencia del 16/09/99 (Fallos 322:2132).

48 "En el caso que el presupuesto correspondiente al ejercicio financiero en que la condena deba ser atendida carezca de crédito presupuestario suficiente para satisfacerla, el Poder Ejecutivo... deberá efectuar las previsiones necesarias a fin de su inclusión en el ejercicio siguiente...". En mérito de ello, dado que el embargo constituye un trámite procesal insoslayable del procedimiento de ejecución de sentencia (art. 502, Código Procesal Civil y Comercial de Corrientes) y que la previsión contenida en el art. $1^{\circ}$ de la ley 25973 no significa una suerte de autorización a las provincias, los municipios y la Ciudad Autónoma de Buenos Aires para no cumplir las sentencias judiciales, pues ello importaría colocarlos fuera del orden jurídico, al haber sido determinado en el caso el quantum adeudado, la deudora debió, para evitar la ejecución forzada, efectuar la previsión presupuestaria correspondiente. Al no haberlo hecho, no cabe la invocación de las prescripciones contenidas en la ley Nacional 25.973. No puede dejar de advertirse que sobre la cuestión, la expuesta es la clara jurisprudencia emanada de la Corte Suprema de Justicia de la Nación (Fallos: 329:4170, sentencia del 26 de septiembre de 2006 en el caso "Roque Reymundo e hijos SACIFAI vs Provincia de San Luís y otros) y sus citas de Fallos: 322:1201; 324:933 y causas C.276.XXXIX "Caja Complementaria de Previsión para la Actividad Docente c. Jujuy, Provincia de s/ ejecución fiscal" y C.903.XXXVII" "Caja Complementaria de Previsión para la Actividad Docente c. Jujuy, Provincia de s/ ejecución fiscal", resoluciones del 8 de noviembre de 2005)". (Voto del Dr. Carlos Rubín, al cual adhieren los otros Sres. Ministros). 
las provincias, los municipios y la Ciudad Autónoma de Buenos Aires para no cumplir las sentencias judiciales, pues ello importaría colocarlos fuera del orden jurídico."

\subsection{LOS CASOS DE URGENCIA DEBIDAMENTE ACREDITADA}

La Corte Suprema de Justicia de la Nación ha declarado inaplicable las restricciones a las ejecuciones de sentencias a los casos en que el sometimiento al régimen implica una degradación o desnaturalización de la sentencia y no una mera dilación de su cumplimiento ${ }^{49}$ ". En el caso, se trataba de una acreedora de 92 años, a quien se debía pagar con bonos a 16 años de plazo. La Corte Suprema dispuso el pago en efectivo, ya que sostuvo que "resulta virtualmente imposible conforme a desenvolvimiento natural de los hechos, que se llegue a percibir la totalidad del crédito que le reconoció el pronunciamiento judicial pasado en autoridad de cosa juzgada."

En tales casos, sea por la vía de la exclusión de la consolidación (si la deuda está comprendida en dicho régimen) o directamente mediante la ejecución de la Sentencia, puede plantearse la inaplicabilidad de la normativa que prohíbe el embargo sobre cuentas de propiedad del Estado. Por supuesto, el acreedor deberá acreditar la concurrencia de tal urgencia, y verificada esta circunstancia por el tribunal interviniente, decretar el embargo, sin más trámite. Le quedará al Estado el planteo de la inexistencia de dichas circunstancias de excepción, pero con el efecto no suspensivo que tienen los recursos contra las medidas cautelares ${ }^{50}$.

\subsection{DAÑOS A LA SALUD Y A LA INTEGRIDAD FÍSICA}

${ }^{49}$ En el leading case "Iachamet, María L. c. Armada Argentina" dictado el 29/04/1993, citado por Dromi (2009, p. 1300).

${ }^{50}$ Las que se verían especialmente reforzadas en su verosimilitud por la existencia de sentencia firme y de las circunstancias de urgencia ya apuntadas. También debe destacarse que en cualquiera de los supuestos el Estado podrá plantear el levantamiento o sustitución, si correspondiera. Ver Gallegos Fedriani (2002). 
También procede la ejecución forzosa y el consiguiente embargo en aquellos casos en los que se ha condenado la reparación de daños a la salud e integridad física ${ }^{51}$ cuya atención no admita dilación.

La Corte Suprema de Justicia ha tenido oportunidad de señalar en principio, la validez del régimen para el pago de las deudas, siempre que la suspensión temporal de los efectos de las sentencias condenatorias, dadas las condiciones de de amortización de tales bonos, no desnaturalizara los derechos patrimoniales reglamentados por aquella ${ }^{52}$.

Sin embargo, el mismo Tribunal ha declarado la inaplicabilidad y la inconstitucionalidad del régimen de consolidación para ciertos casos en los que su aplicación implica no solo un mero diferimiento del pago, sino una desnaturalización de la Sentencia pasada en autoridad de Cosa Juzgada.

En tal sentido la Corte Suprema de Justicia de la Nación se ha expedido en autos "Mesquida, Gregorio Hugo y otro c/ Estado Nacional- Armada Argentina", fallado el 28 de noviembre de 2006, declarando la inconstitucionalidad para el caso concreto del Régimen de Consolidación de la ley 23.544, que también dispone el pago en Bonos de Consolidación a 16 años.

En el caso el máximo Tribunal de nuestro país resolvió declarar la inaplicabilidad de la consolidación dispuesta en el artículo 13 de la ley 25.344 y emplazó al Estado Nacional para que en el ejercicio presupuestario del año 2007 dé cumplimiento a la condena mediante el depósito de las sumas de dinero correspondientes.

\footnotetext{
${ }^{51}$ Derecho expresamente reconocido en la Convención Americana de Derechos Humanos en su Artículo 5. "Derecho a la Integridad Personal 1. Toda persona tiene derecho a que se respete su integridad física, psíquica y moral."

${ }^{52}$ (Fallos: 316: 797 y 3176; 317:1342; 322:82, entre otros).
} 
Resulta interesante el fundamento de los votos de los Dres. Petracchi y Lorenzetti, quienes coinciden: " $6^{\circ}$ ) Que en tal sentido y en cuanto al caso atañe, el art. 27 de la Convención Americana sobre Derechos Humanos establece que las razones de emergencia que afecten la seguridad del estado no autorizan la suspensión, siquiera limitada o transitoria, del derecho a la vida y a la integridad fisica reconocidos en los arts. 4 y 5 de aquélla."

En autos "Morrow de Albanesi" la Corte hizo lugar al recurso de hecho interpuesto por la parte actora (expediente M.790.XLIII), y declaró procedente el recurso extraordinario excluyendo el crédito del régimen de consolidación previsto en la ley $25.344^{53}$. En el considerando citado, la Corte refiere a la doctrina ya sentada en los precedentes "Mesquida" (Fallos: 329:5382) y "Petryszyn" (Fallos: 331:2745), votos del juez Lorenzetti, a cuyos fundamentos y conclusiones se remite.

El fallo citado coincide con lo resuelto -con la anterior integración de la Corte- en autos "Gutiérrez, Alberto c/ Ferrocarriles Argentinos s/ daños y perjuicios ${ }^{\text {"54 }}$ donde se declaró la improcedencia de la consolidación solo para algunos rubros (terapia psiquiátrica, material ortopédico, silla de ruedas y tratamiento kinésico). El tribunal sostuvo que una modificación en el modo de cumplimiento de la sentencia como la que resulta de la ley 23.982, comportaría no solamente una postergación en el ingreso de un bien de naturaleza económica en el patrimonio de la víctima, sino principalmente la frustración de una finalidad esencial del resarcimiento por daños a la integridad psicofísica, cual es el cese del proceso de degradación mediante una rehabilitación oportuna.

\footnotetext{
53 "Morrow de Albanesi, Viviana María y otros cl Estado Nacional - Ministerio de Relaciones Ext., Comercio Internacional y Culto s/ daños y perjuicios" fallado el 17 de agosto de 2010. En igual sentido, con remisión al dictamen de la Procuradora sentencia en autos "Sandobal, Julio c. Ferrocarriles Argentinos, del 02/11/10.

${ }^{54}$ Considerando 11 del fallo dictado el 13 de agosto de 1998 (Fallos 321:1984).
} 
Más amplio fue el criterio favorable a la reparación integral en los autos "Escobar, Héctor Oscar cl Fabrizio, Daniel - Municipalidad de Quilmes y Ejército Argentino" (Fallos: 318:1594).De las constancias de esta causa surgía con claridad que la reparación integral del damnificado exigía la atención inmediata de las secuelas de las gravísimas lesiones sufridas por el actor con motivo del accidente (explosión), a saber, paliar las consecuencias de la ceguera (eventual sustitución de córneas y cristalinos), así como el tratamiento de afecciones de orden psíquico y estético.

Entendió así la Corte que una modificación en el modo de cumplimiento de la sentencia como la que resulta del régimen de la ley 23.982 (la ley de consolidación anterior a la 23.544), comportaría no sólo una postergación en el ingreso de un bien de naturaleza económica en el patrimonio de la víctima, sino, principalmente, la frustración de una finalidad esencial del resarcimiento por daños a la integridad psicofísica, cual es el cese del proceso de degradación mediante una rehabilitación oportuna. Añadió que las consideraciones precedentes autorizaban a concluir que la aplicación en el caso de la ley citada llevaría al desconocimiento sustancial de la sentencia y, al no ser posible -sin forzar la letra o el espíritu de la norma- realizar una interpretación que la hiciera compatible en la especie con la garantía de los artículos 17 y 18 de la Constitución Nacional correspondía confirmar el pronunciamiento de segunda instancia que declaraba su inconstitucionalidad.

En una línea similar de razonamiento, también cabe citar la causa "Petrelli, Claudio Omar c/ Ministerio del Interior- Policía Federal" ${ }^{35}$ en la cual el Tribunal entendió que cabía desestimar los agravios contra la sentencia que en razón de la naturaleza alimentaria del crédito y de la situación de indigencia del demandante excluyó del régimen de consolidación de la ley 25.344 la indemnización por lesiones en actos de servicio. Ello, porque además de la cautela con que deben juzgarse lo atinente a créditos de naturaleza asistencial y alimentaria el accionante

\footnotetext{
${ }^{55}$ Fallos 327:2551.
} 
devino minusválido y necesitaba tratamientos médicos que difícilmente podían ser solventados con el haber de retiro. Se dijo que tratándose de afecciones de orden físico, psíquico y estético derivados del evento dañoso la exclusión de la acreencia del régimen de consolidación se imponía porque un aspecto esencial de la reparación es el cese del proceso de degradación mediante una rehabilitación tempestiva.

De manera más reciente, la Corte ratificó su doctrina en los autos "Tévez, Miguel René y otro c/ Estado Nacional - Ministerio del Interior s/ daños y perjuicios" fallado el 24/09/13. La demanda fue interpuesta por los actores contra el Estado Nacional (Ministerio del Interior), a fin de obtener una indemnización por los daños y perjuicios que derivan del fallecimiento de su hijo, producido por el disparo de un arma reglamentaria. En este caso el Tribunal se remitió a lo resuelto en "Morrow de Albanesi" (Fallos: 330:1404) en cuanto hizo lugar la aplicabilidad del régimen de consolidación de deudas y en consecuencia, desestimó el planteo del estado de pagar la indemnización por daños y perjuicios con bonos de la deuda pública. Los Dres. Lorenzetti y Fayt, por su voto, se remitieron a sus respectivos votos en el precedente "Mesquida" (Fallos: 329:5382).

\subsection{ACREEDOR EN SITUACIÓN DE DESAMPARO}

La situación de desamparo del acreedor se halla expresamente prevista en la normativa que estable la consolidación como una causal de exclusión ${ }^{56}$.

\footnotetext{
${ }^{56}$ Ley 25.344 Artículo 18.- "El Poder Ejecutivo en la reglamentación establecerá un límite mínimo de edad a partir del cual se podrá excluir de la consolidación que se establece por la presente, a titulares de créditos previsionales derivados del régimen general. Asimismo, se podrá disponer la exclusión cuando mediaren circunstancias excepcionales vinculadas a situaciones de desamparo e indigencia en los casos en que la obligación tuviere carácter alimentario”.
} 
La Corte Suprema de Justicia ha declarado que el artículo 18 de la ley 25.344 prevé una excepción al régimen de consolidación y, además, impone a los jueces la obligación de excluir los créditos cuando sus acreedores se encuentren en las especiales condiciones descriptas por el segundo párrafo de la norma (Fallos: 329:5769 y causa A.175.XLIV "Aliprandi, Luisa cl PAMI s/sumario", fallada el 23 de febrero de 2010 $)^{57}$.

En este fallo, es preciso resaltar el voto del Dr. Fayt, quien señala:

2) Que la protección a la inviolabilidad física, psíquica y moral del individuo constituye un rasgo dominante del principio "pro homine", es un derecho preexistente a toda legislación positiva y resulta garantizado por la Constitución Nacional. El ser humano, desde luego, es eje y centro de todo el sistema jurídico y en tanto fin en sí mismo -más allá de su naturaleza trascendente- su persona constituye valor fundamental con respecto al cual los restantes valores tienen siempre carácter instrumental ("Campodónico de Beviacqua", Fallos: 323:3229 y sus citas; y doctrina de "Floreancig", Fallos: 329:2552)... 5) Que la Convención Americana sobre Derechos Humanos, de su lado, es asaz concluyente al respecto, pues su artículo 27 establece que las razones de emergencia que afecten la seguridad del Estado no autorizan la suspensión, siquiera limitada o transitoria, del derecho a la vida y a la integridad física reconocidos en los arts. 4 y 5 de aquélla. Por su parte, el art. 63.1 de dicha convención faculta a la Corte Interamericana a imponer las reparaciones pertinentes cuando esos derechos sean lesionados. En el caso de la privación del derecho a la vida, la restitución al statu qua ante resulta imposible y, por ello, la reparación a que alude el arto 63.1 solo puede asumir la forma de una indemnización sustitutiva, conforme a la doctrina de la Corte Interamericana de Derechos Humanos en los casos "Aloeboetoe", sentencia del 10 de

57 “Cots, Libia Elda c/ Estado Nacional Ministerio de Economía y Obras y Servicios Públicos y otros s/sumario -Incidente de embargo", sentencia del 12/03/13. 
septiembre de 1993, Serie C, N 15; "Bulacio", sentencia del 18 de septiembre de 2003, Serie C, N ${ }^{\circ}$ 100; "Garrido y Baigorria", sentencia de 27 de agosto de 1998, Serie C, $\mathrm{N}^{\circ} 39$, Y sus citas (del voto de los jueces Petracchi y Lorenzetti en la causa "Mesquida").

En el orden local, el Superior Tribunal de Justicia de Corrientes ha tenido oportunidad de dictar sentencia en un expediente en el que se planteó la inaplicabilidad del régimen de consolidación de deudas con este fundamento. En la causa "G. de G., M. S. y otro c/M. C. y Estado de la Provincia de Corrientes s/Ordinario", el Estado provincial fue condenado al pago de una indemnización por daños y perjuicios a un menor discapacitado por lesiones causadas durante el parto, de muy humilde condición económica ${ }^{58}$. En el caso, se trataba de la reparación de los daños causados a un menor durante el parto -desgarro de plexo braquial derecho-. Luego de 14 años de litigio, lograda la sentencia firme, el Estado Provincial pretendía abonar la deuda generada desde el momento del nacimiento del niño, ya adolescente, con bonos de consolidación a 16 (dieciséis) años de plazo.

Planteada la inaplicabilidad del régimen en el caso concreto, la juez de primera instancia hizo lugar al planteo, ordenando el pago en moneda de curso legal y con los intereses fijados en la sentencia original, fallo que fue confirmado por la Cámara de Apelaciones. Llegado el expediente al máximo tribunal provincial, este rechazó el recurso del Estado, sosteniendo que:

"Los agravios expuestos, lejos de demostrar causal de casación, se alzan contra la doctrina de la Corte Suprema de Justicia de la Nación en punto a la aplicabilidad de la hipótesis excepcional del art. 18 de la ley 25.344, que excluye la consolidación cuando

\footnotetext{
${ }^{58}$ Con fecha posterior al fallo se han dictado las Reglas de Brasilia sobre Acceso a la Justicia de las Personas en Condición de Vulnerabilidad, aplicables al caso por tratarse justamente de un menor, sin recursos económicos y discapacitado.
} 
media una situación de desamparo o indigencia, en los supuestos de resarcimientos que tienen, como en el caso, evidente carácter alimentario. En efecto, en el precedente "Camal, Liliana B. y otro c. Hospital Churruca Visca" el Máximo Tribunal del país respondió a una cuestión sustancialmente análoga a la planteada en este caso al Superior Tribunal, en el que dijo "que correspondía aplicar la excepción prevista en el art. 18 de la ley 25.344, que permite excluir obligaciones del régimen de pago en bonos de consolidación de la deuda pública "cuando mediaran circunstancias excepcionales vinculadas a situaciones de desamparo e indigencia en los casos en que la obligación tuviera carácter alimentario". Argumento sobre el particular que desde el punto de vista del menor incapacitado existe una situación de desamparo provocada por la mala praxis medica y que la obligación principal que se deriva de la sentencia, al margen del origen de su causa, adquiere un evidente carácter alimentario, extensivo a los demás rubros de condena (gastos médicos, etc.), ya que son obligaciones originadas en aquella incapacidad, por lo que deben seguir la suerte de la principal (art. 523 y concs., Cód. Civil), en el caso la exclusión del pago mediante el sistema de bonos (C.S.J.N. "Camal, Liliana B. y otro c. Hospital Churruca Visca " 02/06/2003 326:1733 Cita online: $\mathrm{AR} / \mathrm{JUR} / 1571 / 2003)^{, 359}$.

\section{Conclusiones}

El derecho a la tutela judicial efectiva implica la posibilidad de acceder a la justicia, de tramitar el proceso en tiempo y forma, y, por último, lograr el cumplimiento de la sentencia allí obtenida en un plazo razonable.

\footnotetext{
${ }^{59}$ Superior Tribunal de Justicia de Corrientes, en autos "G. de G., M. S. y otro c/M. C. y Estado de la Provincia de Corrientes s/Ordinario” Expte. 4496, Sentencia del 02/05/12.
} 
De nada sirve la existencia de una vía de revisión de la conducta de la Administración, cuando ante los supuestos concretos de responsabilidad que se traducen en el pago de sumas de dinero, dicha sentencia no puede cumplirse efectiva y oportunamente. En tales casos, resultan gravemente afectadas las garantías del debido proceso, la tutela judicial efectiva y del derecho de propiedad del administrado vencedor en el litigio. Y sobre todo se corre el riesgo de que se vulneren derechos fundamentales de la persona y se prescinda de la preocupación por arribar a una decisión objetivamente justa en los casos concretos. De así ocurrir, la solución sería frontalmente contraria al propósito de "afianzar la justicia", enunciado en el Preámbulo de la Constitución Nacional ${ }^{60}$.

Por ello, resumimos lo hasta aquí expuesto en las siguientes conclusiones:

a) El principio general es que las Provincias pueden ser ejecutadas y sus bienes embargados en el caso de sentencias condenatorias.

b) Las normas federales y locales que otorgan a las Provincias el privilegio de la inembargabilidad solo resultan oponibles cuando no impliquen, en el caso concreto, degradar y desconocer la Sentencia firme, afectando así el derecho al debido proceso, a la tutela judicial efectiva y el derecho de propiedad.

c) Los principales supuestos en que ello tiene lugar son:

-Cuando la deuda, no obstante estar comprendida en el régimen de consolidación no es satisfecha con la entrega de los bonos correspondientes, y tampoco se cumple con el pago en efectivo,

-Cuando no se realiza la imputación presupuestaria y el pago en el ejercicio siguiente o en un plazo razonable, para el caso de deudas no consolidadas,

\footnotetext{
${ }^{60}$ CSJN, “Pedraza, Héctor Hugo cl ANSeS s/Acción de amparo", sentencia del 6/05/14, considerando 11.
} 
-En los casos de urgencia debidamente acreditada;

-En procesos en los que se ha reclamado la reparación de daños a la salud o integridad física; y

- En las situaciones especiales de desamparo o vulnerabilidad del acreedor.

\section{REFERENCIAS BIBLIOGRÁFICAS}

BALBIN, C. F. (2013) Tratado de Derecho Administrativo. Buenos Aires.

CASSAGNE, J. C. (1998), Derecho administrativo (6 ${ }^{\mathrm{a}}$ ed.), Buenos Aires: Abeledo-Perrot.

DROMI, R. (2009) Derecho Administrativo (12 ed.), Buenos Aires - Madrid - México: Ciudad Argentina - Hispania Libros.

GALLEGOS FEDRIANI, P. (2002) Las Medidas Cautelares contra la Administración Pública. Buenos Aires: Ábaco de Rodolfo Depalma.

GALLEGOS FEDRIANI, P. (2007) Ejecución de sentencias contra el Estado Nacional, en CASSAGNE, J. C. -dir.- (2007), Tratado de Derecho Procesal Administrativo, 2, Buenos Aires: La Ley.

GELLI, M. A. (2008), Constitución de la Nación Argentina. Comentada y concordada (4 ed.), Buenos Aires: La Ley..

GORDILLO, A. (2009) Tratado de Derecho Administrativo (10 ${ }^{\mathrm{a}}$ ed.), Buenos Aires: F.D.A.

MIDON, M. A. R. (2008) La nueva Constitución de Corrientes Corrientes: Mave. 
REVIDATTI, G. A. (1986) Lo Contencioso Administrativo, Corrientes: Cicero Ediciones.

RUBIN, C. (2008) Procedimiento Contencioso Administrativo de la Provincia de Corrientes (1 ${ }^{\mathrm{a}}$ ed.) Corrientes: Mave.

\section{CURRICULUM VITAE}

Especialista en Derecho Administrativo (UNNE). Adscripto a la Cátedra A de Derecho Administrativo I de la Facultad de Derecho y Ciencias Sociales y Políticas de la UNNE.

Correo electrónico: estudiogoldfarb@ hotmail.com 